\section{Initiation of Explosives by Adiabatic Com- pression of their own Vapour}

Prevrous work has shown that the sensitivity of liquid explosives to impact is greatly increased by the presence of minute gas bubbles ${ }^{1}$. The initiation is of a thermal nature and is due to the adiabatic compression and heating of the trapped bubbles. A simple method of including a gas space in an explosive is to spread it as a small annulus on a flat anvil. When this is struck with a flat hammer, the small amount of gas in the centre is trapped and compressed.

In these experiments the size of the annulus was such that the initial volume of the gas space was c. $5 \times 10^{-5}$ c.c. With nitroglycerine in air at atmospheric pressure, regular explosions are obtained with an impact energy of $300-500 \mathrm{gm}$. $\mathrm{cm}$. When the nitroglycerine is spread as a continuous film so that gas spaces are not present, very high impact energies are necessary $\left(10^{5}-10^{6} \mathrm{gm}\right.$. cm. $)$. At low initial air pressures (less than $10^{-5} \mathrm{~mm}$. mercury), it is found that the annulus still exercises a similar influence in increasing the sensitivity, and explosions are still obtained with impact energies of c. $500 \mathrm{gm}$. cm. Although the other gases have been pumped out, the vapour pressure of nitroglycerine itself at room temperature is c. $10^{-3} \mathrm{~mm}$. The experiments suggest that the initiation of the explosion under these conditions is due to the compression and adiabatic heating of the nitroglycerine vapour itself. This would assume that the vapour is not condensed during the rapid compression produced by the impact. The same high sensitivity is obtained when the evacuated space is filled with $50 \mathrm{~mm}$. of methyl nitrate vapour, another explosive similar to nitroglycerine. This supports the above view.

These results have a bearing on the handling of liquid explosives. The compression of any small space, whether filled with a gas or with the vapour of explosive only, may initiate an explosion. Such a condition could arise, for example, during the collapse of bubbles formed by cavitation.

When a solid such as P.E.T.N. is distributed on the anvil as an annulus rather than as a uniform film of crystals, an increase in the explosion efficiency is again observed: the energy necessary to give an explosion efficiency of 50 per cent is $2.8 \times 10^{4} \mathrm{gm}$. $\mathrm{cm}$. for an annulus and $7 \cdot 1 \times 10^{4} \mathrm{gm}$. cm. for a continuous film. This increase in efficiency due to the annulus occurs both when the air pressure is initially one atmosphere, and when it is initially less than $10^{-5} \mathrm{~mm}$. and the total pressure, including that of the explosive vapour, is $c .10^{-4} \mathrm{~mm}$. Again, it would appear that the compression of the vapour of the explosive may initiate the reaction.

The behaviour of some solid explosives under impact thus shows many similarities to that of the liquid explosives. Apparently the air spaces which are present between the crystals of solid explosive are sealed off by local melting or plastic flow during the impact, and the adiabatic compression of the air or vapour in these gas spaces may initiate the explosion.

Research Group on the Physics and

A. YoFFe

Chemistry of Rubbing Solids,

Department of Physical Chemistry,

$$
\text { Cambridge. }
$$

Nov. 15 .

1 Bowden. F. P., Mulcahy, M. F. R., Vines, R. G., and Yoffe, A.,

\section{Acetylation of Sugars}

THE acetylation of sugars has hitherto involved the use of acetic anhydride and a catalyst such as sodium acetate ${ }^{1}$, zine chloride ${ }^{2}$, sulphuric acid $^{3}$ or pyridine $e^{4}$ We have shown that glucose may be acetylated rapidly by means of a mixture of acetic anhydride and acetic acid if a small amount of perchloric acid is added to act as a catalyst ${ }^{5}$. No external application of heat is necessary to aid the reaction. By pouring the acetylation mixture into water, an almost quantitative yield of $\alpha$-pentacetyl glucose is produced. This new procedure does not afford crystalline acetyl derivatives of galactose or mannose; but it works well for the acetylation of maltose, difructofuranose anhydride, $\alpha$-methylglucoside, and polyhydric alcohols such as mannitol, sorbitol, erythritol, arabitol and pentaerythritol.

The method offers a rapid route to the formation of acetobromglucose and acetobrommaltose, inasmuch as the intermediate isolation of the acetylated sugars can be dispensed with and the acetylation reaction mixture treated directly with hydrogen bromide (ef. ref. 3). The advantages offered by this process arise not only from the fact that there is a great saving in time but also that the yields are improved. Thus acetobromglucose and acetobrommaltose, prepared as indicated above, give upon treatment in the usual manner with methyl alcohol in the presence of silver carbonate the corresponding tetracetyl $\beta$ methylglucopyranoside and heptacetyl $\beta$-methylmaltoside in yields of 55 per cent and 53 per cent respectively. Hitherto yields of 36 per cent and 24 per cent respectively have been recorded for the preparation of these glycosides by methods $6, ?$ involving the intermediate isolation of the acetates before treatment with hydrogen bromide.

A more detailed account of these experiments will be published elsewhere.

A. E. Hills Laboratories, University,

Edgbaston, Birmingham 15. Nov. 17.

1 Tanret, Bull. Soc. Chim., 13 (3), 261 (1895). Liebermann and H8rmann, Ber., 11, 1618 (1878). Herzfeld, Ber., 13, 265 (1880).

Hudson and Dale, J. Amer. Chem. Soc., 37, 1264 (1915).

- Redemann and Niemann, Organic Synthesis, 22, 1.

- Behrend and Roth, Annalen, 331, 364 (1904).

s Conant and Bramann, J. Amer. Chem. Soc., 50, 2305 (1928). Whitman and Schwenk, J. Amer. Chem. Soc., 68, 1865 (1946).

- Fischer, Ber., 49, 584 (1916). Hudson and Dale, J. Amer. Chem. Soc. 37,1264 (1915).

'Irvine and Black, J. Chem. Soc., 1, 862 (1926). Schoch, Wilson and Hudson, J. Amer. Chem. Soc., 64, 2871 (1942).

\section{Paper Chromatography of Flavine Nucleotides}

PARTition chromatography on paper ${ }^{1}$ has not hitherto been reported for the analysis of riboflavine, its nucleotides and derivatives. However, 'Collidine', and a butyl alcohol-acetic acid mixture (shake 4 parts butyl alcohol with 1 part glacial acetic acid and 5 parts water, and use the upper layer), are two very suitable solvents for separating various flavine com. pounds, identified by their characteristic green fluorescence in ultra-violet light, which will detect as little as $0.01 \mu \mathrm{gm}$. flavine on the paper. The separated substances can be easily and quantitatively removed from the paper by the method of Dent ${ }^{2}$ and used for enzymic or other experiments. 